\title{
INK4a/ARF mutations accelerate lymphomagenesis and promote chemoresistance by disabling p53
}

\author{
Clemens A. Schmitt, Mila E. McCurrach, Elisa de Stanchina, Rachel R. Wallace-Brodeur, \\ and Scott W. Lowe ${ }^{1}$
}

Cold Spring Harbor Laboratory, Cold Spring Harbor, New York 11724 USA

\begin{abstract}
The INK4a/ARF locus encodes upstream regulators of the retinoblastoma and p53 tumor suppressor gene products. To compare the impact of these loci on tumor development and treatment response, the E $\boldsymbol{\mu} \boldsymbol{u}-\boldsymbol{m y c}$ transgenic lymphoma model was used to generate genetically defined tumors with mutations in the INK4a/ARF, Rb, or p53 genes. Like p53 null lymphomas, INK4a/ARF null lymphomas formed rapidly, were highly invasive, displayed apoptotic defects, and were markedly resistant to chemotherapy in vitro and in vivo. Furthermore, INK4a/ARF $F^{-/-}$lymphomas displayed reduced $p 53$ activity despite the presence of wild-type p53 genes. Consequently, INK4a/ARF and p53 mutations lead to aggressive tumors by disrupting overlapping tumor suppressor functions. These data have important implications for understanding the clinical behavior of human tumors.
\end{abstract}

[Key Words: INK4a/ARF locus; lymphomagenesis; chemo resistance; p53]

Received August 10, 1999; revised version accepted August 31, 1999.

Mutations in the $p 53$ tumor suppressor gene and at the INK4a/ARF locus are the two most frequent genetic lesions identified in human tumors (for reviews, see Haber 1997; Ruas and Peters 1998). p53 is a sequence-specific DNA-binding protein that can induce cell-cycle arrest or apoptosis in response to pathological insults such as DNA damage and expression of mitogenic oncogenes (Kastan et al. 1991, 1992; Lowe and Ruley 1993; Hermeking and Eick 1994; Serrano et al. 1997; for reviews, see Giaccia and Kastan 1998; Prives 1998). As a consequence, inactivation of $p 53$ can promote oncogenic transformation and resistance to many anticancer agents (for reviews, see Giaccia and Kastan 1998; Prives 1998; Wallace-Brodeur and Lowe 1999). The INK4a/ARF locus encodes two tumor suppressors, designated $\mathrm{p} 16^{\mathrm{INK} 4 \mathrm{a}}$ and p19 ${ }^{\mathrm{ARF}} \cdot \mathrm{p} 16^{\mathrm{INK} 4 \mathrm{a}}$ is a cyclin-dependent kinase inhibitor that acts upstream of the retinoblastoma $(\mathrm{Rb})$ protein to promote cell-cycle arrest (Serrano et al. 1993; for reviews, see Haber 1997; Ruas and Peters 1998). p19 ARF is translated in an alternative reading frame from $\mathrm{p} 16^{\mathrm{INK} 4 \mathrm{a}}$ and activates p53 by interfering with its negative regulator, Mdm2 (Kamijo et al. 1998; Pomerantz et al. 1998; Stott et al. 1998; Zhang et al. 1998; see also Tao and Levine 1999; Weber et al. 1999; Zhang and Xiong 1999). Consequently, INK $4 a / A R F$ mutations can disable both the $\mathrm{Rb}$ and $\mathrm{p} 53$ tumor suppressor pathways.

${ }^{1}$ Corresponding author.

E-MAIL lowe@cshl.org; FAX (516) 367-8454.
Recent studies indicate that $\mathrm{p} 19^{\mathrm{ARF}}$ acts as an essential intermediate in oncogene signaling to p53 (Bates et al. 1998; de Stanchina et al. 1998; Palmero et al. 1998; Pomerantz et al. 1998; Zindy et al. 1998; for review, see Sherr 1998). For example, oncogenes such as E1A or cmyc induce $A R F$ message and protein in normal mouse embryo fibroblasts, which correlates with their ability to activate p53 and promote apoptosis. In contrast, these oncogenes fail to activate p53 in ARF-null cells, and promote proliferation without substantial apoptosis (de Stanchina et al. 1998; Zindy et al. 1998). Together, these studies indicate that $\mathrm{p} 19^{\mathrm{ARF}}$ acts as part of a p53-dependent fail-safe mechanism to counter hyperproliferative signals. Interestingly, p19 ${ }^{\mathrm{ARF}}$ is not induced by DNA damage (Kamijo et al. 1997; Stott et al. 1998) but can cooperate with DNA damaging agents to induce apoptosis in oncogene expressing cells (de Stanchina et al. 1998). These studies predict that disruption of $A R F$, or the INK4a/ARF locus, should cooperate with mitogenic oncogenes during tumor development, in part, by disabling p53.

p53 mutations have been associated with aggressive cancers, poor prognosis, and drug resistance in human patients (Schmitt and Lowe 1999; Wallace-Brodeur and Lowe 1999). In principle, tumors with INK4a/ARF mutations might also display aggressive characteristics owing to extragenic defects in the $\mathrm{p} 53$ pathway. To test this, we examined the impact of INK4a/ARF mutations on tumor development and therapy using the E $E$ - $m y c$ transgenic mouse. These mice constitutively express c-Myc 
in the B-cell lineage and develop B-cell lymphoma with associated leukemia (Adams et al. 1985; Adams and Cory 1991). This model was chosen for several reasons. First, because Myc induces p19 $\mathrm{ARF}$ and activates p53 in cultured fibroblasts (Zindy et al. 1998), Ep1-myc transgenic mice provide a relevant setting for comparing the impact of INK4a/ARF and p53 mutations on tumor behavior. Second, E 1 - $m y c$ lymphomas/leukemias are easily monitored by lymph-node palpation or blood smears, a property that facilitates studies examining tumor responses to therapy. Finally, essentially pure tumor cells can be isolated from lymph nodes and studied ex vivo or expanded in genetically matched nontransgenic recipients. The tractable nature of this model is in stark contrast to human systems, which suffer from difficulties in obtaining well-characterized and comparable clinical material.

\section{Results}

Loss of the INK4a/ARF locus accelerates lymphomagenesis similarly to loss of p53

To generate lymphomas with defined alterations, we crossed the E $\not 1-m y c$ transgenic to mice heterozygous for germ-line deletions in the $R b\left(R b^{+/-}\right), I N K 4 a / A R F$ $\left(\right.$ INK4a $\left./ A R F^{+/-}\right)$, or $p 53\left(p 53^{+/-}\right)$genes (Jacks et al. 1992,

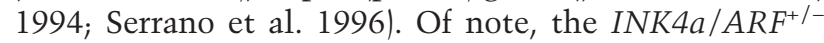
animals harbor deletions that disrupt both $\mathrm{p} 19^{\mathrm{ARF}}$ and p16 ${ }^{\mathrm{INK} 4 \mathrm{a}}$, thereby recapitulating the common gross deletions seen in human tumors (Haber 1997; Ruas and Peters 1998). The onset of E $11-m y c$ lymphomas in $R b^{+/-}$ animals was variable (Fig. 1A; green, b) and only slightly accelerated relative to that observed in the wild-type background (hereafter referred to as control) (Fig. 1A; black, a). In contrast, the onset of E 1 -myc lymphomas in INK $4 \mathrm{a} / \mathrm{ARF}^{+/-}$and $\mathrm{p} 53^{+/-}$animals (Fig. 1A; blue, c, and red, d) was highly reproducible and greatly accelerated compared with controls $(P<0.0001$ each); the timing of

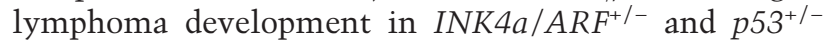
mice was virtually identical. Cell surface staining confirmed that all lymphomas were of the B-cell lineage (B220+; Thy1.2-), whereas the distribution of pre-B (IgM-) and B (IgM+) was similar between the genotypes.

These data imply that p53 and products of the INK4a/ $A R F$ locus limit Myc-induced lymphomagenesis. Concordantly, Ep1-myc lymphomas arising in the $p 53^{+/-}$and INK $4 a / A R F^{+/-}$animals invariably lost the wild-type $p 53$ or INK4a/ARF allele (93.8\% and $88.2 \%$, respectively) (Fig. 1B). Hence, these lymphomas were either p53-null $\left(p 53^{-/-}\right)$or INK4a/ARF-null (INK4a/ARF $\left.F^{-/-}\right)$. Virtually all control (6 out of 7), $R b^{+/-}(4$ out of 4$)$, and INK4a) $A R F^{-1-}(9$ out of 9$)$ tumors retained wild-type p53 as indicated by RT-PCR and sequencing of $p 53$ exons 4-8 (data not shown). The one p53 mutation identified (H190R in mouse; H193R in human) corresponds to a mutation observed in B-cell leukemias and a Burkitt's lymphoma (Beroud and Soussi 1998). Deletions of the INK4a/ARF locus were noted in $20 \%$ of control and $R b^{+/-}$tumors (4 out of 20 ) but never in $p 53^{-/-}$tumors $(0$ out of 10) (data not shown). In no instance did lympho-
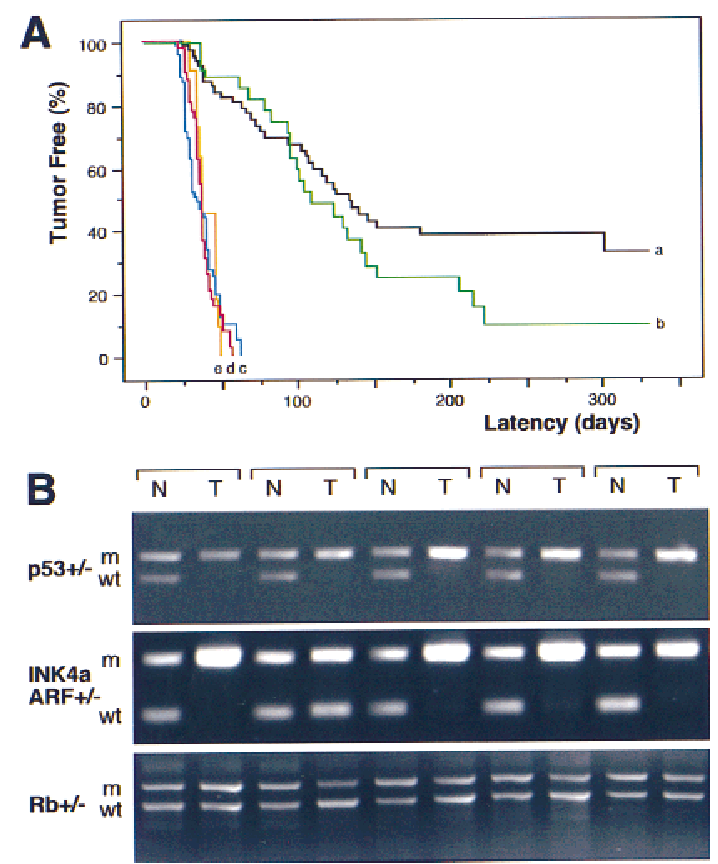

Figure 1. Tumor development in E $\mu-m y c$ transgenic mice. $(A)$ Lymphoma incidence in E $E-m y c$ transgenic mice in the wildtype (control) background ( $n=65$; black, a) and in mice heterozygous for $R b(n=39$; green, b), INK4a/ARF $(n=41$; blue, c), p53 ( $n=73$; red, d), and INK4a/ARF; p53 double heterozygotes ( $n=11$; orange, e). By day 70 , all $p 53^{+/-}$and $I N K 4 a / A R F^{+/-}$mice developed lymphoma, whereas $>75 \%$ of $R b^{+/-}$and control mice remained tumor free. $(B)$ Matched normal $(\mathrm{N})$ and tumor $(\mathrm{T})$ DNA were isolated from tail and lymph nodes and analyzed by allele-specific PCR for the targeted gene $[(\mathrm{m})$ mutated allele; $(\mathrm{wt})$ wild-type allele]. Shown are results from five $E \mu-m y c$ transgenic mice in each genetic background. Note that tumors aris-

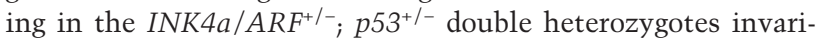
ably lost the wild-type $p 53$ allele but never the INK4a/ARF allele.

mas arising in $\mathrm{Rb}^{+/-}$animals lose the wild-type $R b$ allele (Fig. $1 \mathrm{~B}$ ), confirming that $\mathrm{Rb}$ loss has a minimal impact on Myc-induced lymphomagenesis. Because $\mathrm{Rb}$ and p16 INK4a loss should produce similar phenotypes (Haber 1997; Ruas and Peters 1998), these data imply that p19 ${ }^{\mathrm{ARF}}$ is crucial for suppressing Myc-induced lymphomagenesis. The onset of En-myc lymphomas is markedly accelerated in ARF-deficient mice (Eischen et al. 1999).

\section{Loss of INK4a/ARF or p53 promotes lymphoma spreading into visceral organs}

INK4a/ARF $F^{-/-}$and $p 53^{-/-}$lymphomas were highly invasive and infiltrated into various nonlymphoid organs. For example, in mice bearing INK $4 a / A R F^{-/-}$and $p 53^{-/-}$lymphomas, we observed extensive periportal invasion and spreading of lymphoma cell clusters throughout the liver parenchym and massive malignant pulmonary infiltration as consolidated aggregation of large mononuclear cells and within the distended interstitial capillaries (Fig. 
2). Also, neoplastic cells accumulated in the submucosa of the urinary bladder, within the kidneys, in the serosal and mesenteric surfaces of the gasterointestinal tract, and along the meninges. In contrast, tumors in mice bearing control or $R b^{+/-}$lymphomas showed little systemic infiltration or remained localized to the lymph nodes and blood compartment despite a similarly large tumor burden. The invasive behavior of INK4a/ARF-/and $p 53^{-/-}$tumors was reproduced following transplantation of the tumors into syngenic recipients (data not shown) and is indicative of a highly aggressive disease.

\section{INK4a/ARF ${ }^{-/-}$lymphomas show an apoptotic defect but no genomic instability}

p53 mutations can decrease cell death, increase proliferation, and produce chromosomal instability depending on context (Schmitt and Lowe 1999; Wallace-Brodeur and Lowe 1999). To determine the impact of INK4a/ARF and p53 mutations on these characteristics, we examined apoptosis, mitotic index, and DNA content in control, INK4a/ARF-/- and $p 53^{-/-}$lymphomas. As revealed by histological staining and TUNEL (terminal deoxynucleotidyl transferase d $\underline{\text { UTP }}$ nick end labeling), control lymphomas contained large numbers of apoptotic cells that clustered (Fig. 3A). Apoptosis was much reduced in INK4a/ARF ${ }^{-/-}$or $p 53^{-/-}$lymphomas, and the apoptotic cells that appeared were isolated. Furthermore, primary INK4a/ARF $F^{-/-}$and $p 53^{-/-}$lymphoma cells explanted into culture survived much better than controls (Fig. 3B). The mitotic index (Fig. 3C) and S-phase fraction (Fig. 3D) of all lymphoma types analyzed were similar, implying that INK4a/ARF or $p 53$ mutations did not affect the proliferation rate. DNA content analysis revealed one notable difference: Whereas most of the $p 53^{-/-}$tumors were aneuploid (10 out of 12), most control and INK4a) $A R F^{-/-}$tumors remained diploid (13 out of 14 and 13 out of 14, respectively) (Fig. 3D). Together, these data demonstrate that highly aggressive lymphomas can occur in the absence of chromosomal instability and imply that the aggressive nature of INK4a/ARF-I- and $p 53^{-/-} \mathrm{lym}-$ phomas is due to an apoptotic defect.

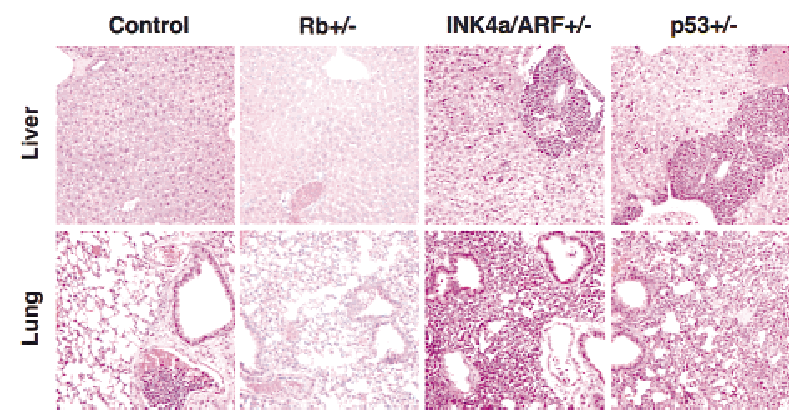

Figure 2. Invasiveness of $E \not 1-m y c$ lymphomas in liver and lung (H.E. staining, 200 $\times$ ). Representative examples of control, $\mathrm{Rb}^{+/-}$, INK4a/ARF $F^{-1-}$, and $p 53^{-/-}$lymphomas are shown. Note the malignant embolus in the pulmonary vessel of the control-nonetheless, the lung itself remained tumor free. The relative congestion of the $R b^{+/-}$lung is a postmortem artifact.
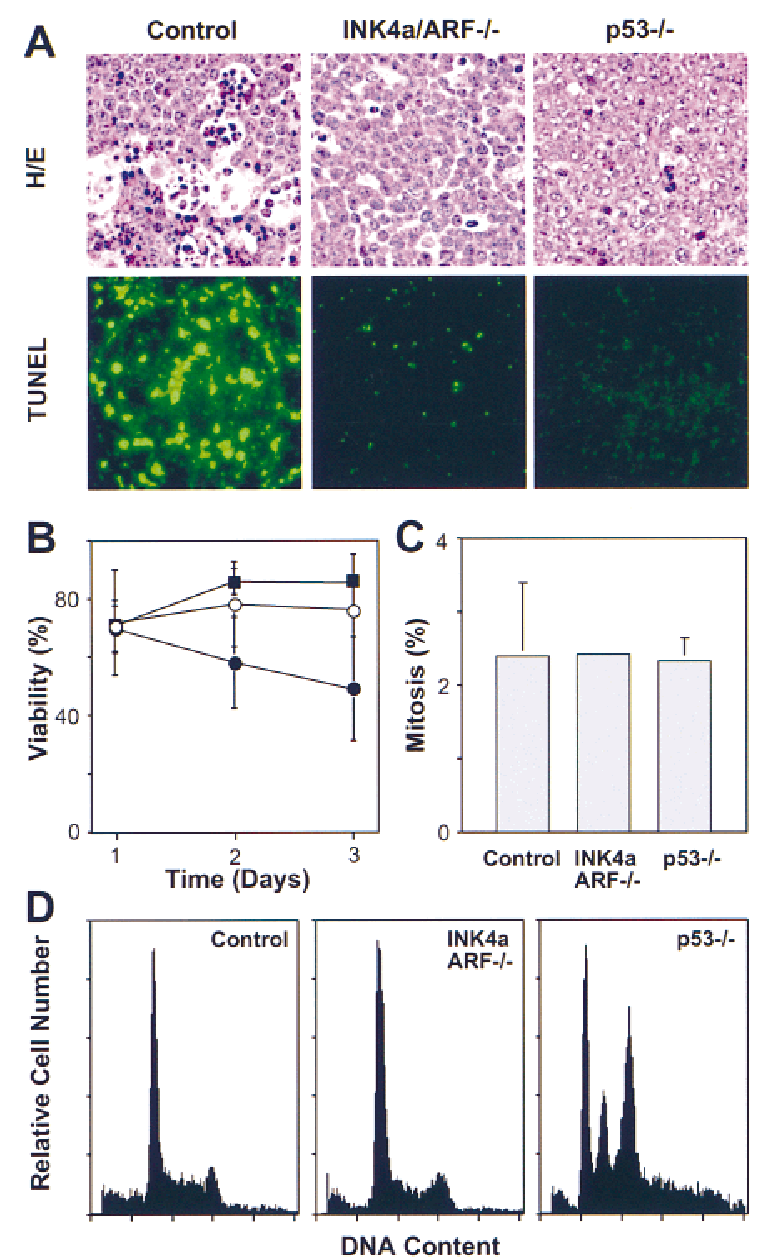

Figure 3. Analysis of apoptosis, proliferation, and chromosomal stability in Epl-myc lymphomas. (A) Apoptosis in situ (lymph nodes) was visualized by HE staining and TUNEL. The reduced

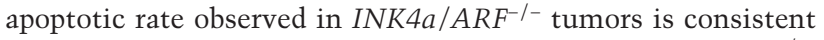
with a similar defect observed in the ocular lens of $\mathrm{Rb}^{-/-}$; INK4a/ARF-/- embryos (Pomerantz et al. 1998). (B) Viability of

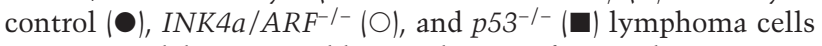
as measured by trypan blue exclusion after explanting onto feeder cells. $(C)$ Proliferation as estimated by the percentage of mitotic figures in HE-stained lymphoma sections. (D) DNA content analysis of primary E $p$-myc lymphoma. The S-phase fractions of control $(30.25 \% \pm 8.31, n=9)$ and INK4a/ARF-/$(29.98 \% \pm 6.39, n=10)$ were virtually identical, whereas subG1 fractions of control $(3.26 \% \pm 3.17)$ and INK4a/ARF-/$(0.30 \% \pm 0.56) \quad$ lymphomas were significantly different $(P=0.0097)$. Note that sub-G1 assessment recognizes only late apoptotic cells and gives lower estimates than TUNEL. Calculations of S-phase and sub-G1 fraction in $p 53^{-/-}$lymphomas were impossible due to aneuploidy. Representative profiles are shown. Note that low frequency of aneuploidy in control and INK4a/ARF $F^{-/-}$lymphomas ( 1 of 14 and 1 of 14 , respectively) is consistent with the overall p53 mutation rate we observed in these tumors.

\section{INK4a/ARF mutations compromise p53 function in vivo}

The remarkable similarities between INK4a/ARF $F^{-/-}$and $p 53^{-/-}$lymphomas suggest that these mutations disrupt 
overlapping tumor suppressor functions. In agreement, En-myc lymphomas arising in mice heterozygous for

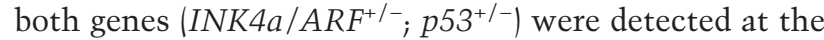
same time as lymphomas in the INK $4 a / A R F^{+/-}$and $p 53^{+/-}$animals (50th percentile $=38$ vs. 38 vs. 36 days to onset, respectively) (Fig. 1A; orange, e) and never displayed coincident loss of both wild-type INK4a/ARF and p53 alleles (data not shown). Therefore, inactivation of both loci produces no additional advantage to E $\not 1-m y c$ lymphomas. In cultured fibroblasts, Myc activates p53 in an ARF-dependent manner (Zindy et al. 1998). Similarly, control Epl-myc lymphomas displayed a variable but consistent increase in p53 levels and activity (as measured by expression of the p53 target p21) compared with normal splenocytes (Fig. 4A, cf. $\mathrm{N}$ with control). This increase appeared dependent on the INK4a/ARF locus, because INK4a/ARF $F^{-/-}$tumors displayed only a modest induction of p53 and virtually no increase in p21 (Fig. 4A). This implies that INK4a/ARF mutations can accelerate tumor progression and impair apoptosis by compromising p53 function.

\section{INK4a/ARF mutations reduce p53 activation following chemotherapy}

The fact that $19^{\mathrm{ARF}}$ can cooperate with DNA-damaging agents to induce p53 and apoptosis raises the possibility that INK4a/ARF mutations might compromise cancer therapy (de Stanchina et al. 1998). To test this, we examined the impact of INK4a/ARF or p53 mutations on

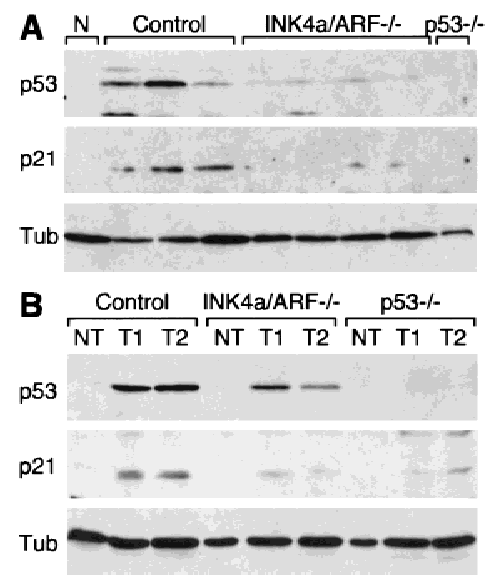

Figure 4. p53 levels and activity in untreated and CTX-treated El1-myc lymphomas. (A) Control (three independent tumors), INK4a/ARF-l- (four independent tumors), and $p 53^{-/-}$lymphoma lysates were probed against $\mathrm{p} 53$ and the p53 downstream target p21, reflecting p53's activity. Normal splenocytes (N) from nontransgenic mice were used for comparison. Tubulin (Tub) was used to verify protein loading. (B) Control, INK4a/ $A R F^{-1-}$, and $p 53^{-/-}$lymphoma cells were isolated from lymph nodes of untreated animals (NT) or $4 \mathrm{hr}$ after CTX treatment (T1 and T2) and analyzed as above. For each tumor type, T1 and T2 were derived from separate primary tumors, whereas NT and T1 represent reconstituted lymphomas derived from the same primary tumor. drug-induced responses in reconstituted lymphomas or following short-term culture. Reconstituted lymphomas were produced following intravenous injection of primary lymphoma cells into syngenic (nontransgenic) recipients, thereby eliminating the possibility that secondary malignancies might complicate scoring tumor responses. Importantly, these lymphomas were histopathologically identical to their respective primary tumors (data not shown). In control lymphomas, p53 and p21 levels were dramatically increased $4 \mathrm{hr}$ after treatment with cyclophosphamide (CTX), an alkylating agent used to treat human leukemia and lymphoma (Fig. 4B). p53 and p21 levels also increased in INK4a/ARF-I- lymphomas, although this response was consistently reduced compared with controls. Therefore, in E lymphoma cells, INK4a/ARF mutations can reduce p53 activation by a DNA damaging agent.

\section{INK4a/ARF mutations affect the short-term response to anticancer treatment}

Loss of either INK4a/ARF or p53 had a profound effect on drug-induced cell death in vitro and in vivo. In shortterm cultures, INK $4 a / A R F^{-/-}$or $p 53^{-/-}$lymphomas displayed a marked resistance to mafosphamide (a CTX analog active in vitro) (Fig. 5A). In peripheral blood, control animals harboring associated leukemias displayed a nearly 100-fold reduction in the white blood cell count (WBC) within $4 \mathrm{hr}$ of CTX therapy, which coincided with a 6- to 10-fold accumulation of apoptotic cells (Fig. 5B,C). In contrast, INK $4 a / A R F^{-/-}$and $p 53^{-/-}$leukemias took 12-24 hr to achieve a similar reduction. Apoptosis was not detectable, perhaps because the slow death rate allowed clearance of apoptotic cells before they could accumulate. In lymph nodes, control lymphomas displayed massive apoptosis $5 \mathrm{hr}$ after CTX therapy, whereas the INK4a/ARF $F^{-/-}$and $p 53^{-/-}$lymphomas displayed substantially fewer dying cells (Fig. 5D).

\section{INK4a/ARF mutations impair the long-term response} to anticancer treatment

The ultimate determinant of drug-induced cell kill is tumor regression and the duration of remission. To assess long-term responses, animals harboring control, INK $4 a / A R F^{-/-}$, or $p 53^{-/-}$lymphomas were treated with CTX and monitored for remission and relapse by lymph node palpation and WBC. Control lymphomas responded extremely well to CTX treatment, and $>70 \%$ remained in remission during the 100-day observation period (Fig.

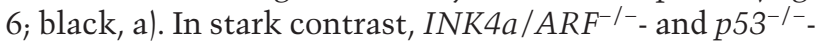
null tumors displayed an extremely poor response to CTX therapy: Despite initial responses, only 1 out of 14 $p 53^{-/-}$and 4 out of 35 INK4a/ARF $F^{-/-}$lymphomas remained in remission. $p 53^{-/-}$tumors (Fig. 6; red, c) were the most relapse prone (50th percentile $=20$ days in remission, $P<0.0001$ compared with control), although the defect in the INK4a/ARF ${ }^{-/-}$response (Fig. 6; blue, b) was also highly significant (50th percentile $=28$ days in 

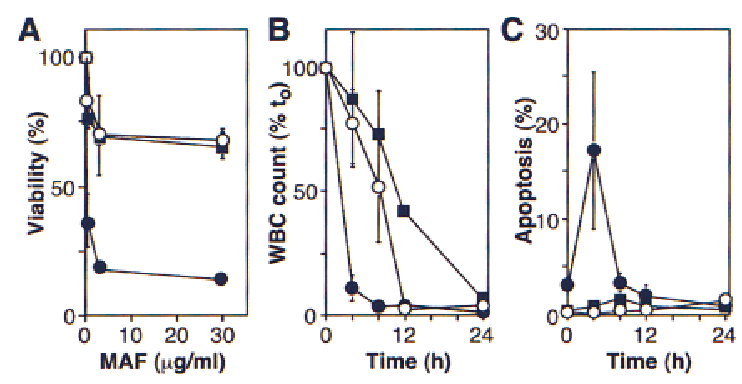

D
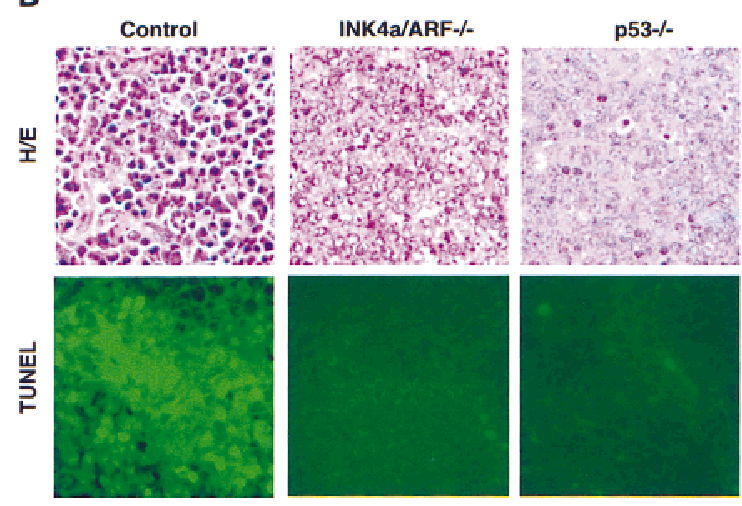

Figure 5. INK4a/ARF, $p 53$, and short-term response to chemotherapy. (A) Explanted control (৩), INK4a/ARF-1- $(O)$, and $p 53^{-/-}$(ロ) lymphoma cells were treated with mafosphamide (MAF). Viability was analyzed after $24 \mathrm{hr}$ by trypan blue exclusion; each value was normalized to untreated controls and represents the mean \pm S.D. of two independently derived tumors reproduced in duplicate. $(B)$ Leukemic mice were treated with CTX, and blood samples were taken at the indicated times. Each $\mathrm{WBC}$ is relative to its pretreatment value and represents the mean \pm S.D. of three independent leukemias. Symbols are as in $A$. (C) Same as in $B$, except that blood samples were ethanolfixed and stained with the DNA fluorochrome DAPI to visualize the chromatin condensation characteristic of apoptotic cells. Each value reflects the percentage of cells with apoptotic morphology (of 200 cells counted) and represents the mean \pm S.D. of three independent leukemias. Symbols are as in $A$. (D) HE staining and TUNEL of lymph nodes harboring control, INK4a/ARF ${ }^{-/-}$, and $p 53^{-/-}$lymphomas $5 \mathrm{hr}$ after CTX treatment.

remission, $P=0.0053$ compared with control). The re-

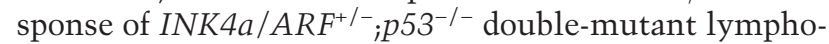
mas (Fig. 6; orange, d) was virtually identical to the $p 53^{-/-}$tumors (50th percentile $=20$ days in remission), and the relapsed tumors never displayed loss of the wildtype INK4a/ARF allele (data not shown). Therefore, although INK4a/ARF mutations promote chemoresistance in the presence of wild-type $p 53$ genes, they confer no additional survival advantage once $p 53$ is mutated. These data demonstrate that INK4a/ARF mutations can compromise therapy, at least in part, by disabling p53.

\section{Discussion}

By comparing the properties of Myc-induced lymphomas in several genetic backgrounds, we provide compelling evidence that INK4a/ARF deletions can impact tumor development and anticancer therapy by compromising p53 function. Like $p 53^{-/-}$tumors, INK4a/ARF $F^{-/-}$lymphomas formed rapidly, were highly invasive, displayed apoptotic defects, and were markedly resistant to chemotherapy. Furthermore, INK4a/ARF $F^{-/}$lymphomas displayed attenuated p53 activity despite the presence of wild-type $p 53$ genes. The profound impact of INK4a/ $A R F$ and p53 mutations on Myc-induced lymphomagenesis indicates that the ARF-p53 pathway contributes to oncogene-induced cell death in developing tumors and underscores the importance of this fail-safe mechanism in tumor suppression (also see Eischen et al. 1999; Jacobs et al. 1999). Furthermore, that INK4a/ARF mutations can compromise drug-induced cell death in E phomas implies that cooperative effects between oncogenes (in part via ARF) and DNA damage contribute to the remarkable drug sensitivity of some tumors.

The only substantial difference between INK4a/ $A R F^{-1-}$ and $p 53^{-/-}$lymphomas was that the INK4al $A R F^{-/-}$lymphomas remained diploid, whereas the $p 53^{-/-}$lymphomas were aneuploid. This pattern is reminiscent of $A R F^{-/-}$and $p 53^{-/-}$fibroblasts (Kamijo et al. 1997) and implies that $19^{\mathrm{ARF}}$ does not control the p53 functions involved in maintaining chromosome stability. Although we have not analyzed the secondary changes arising in INK $4 a / A R F^{-/-}$tumors in detail, these data argue that invasive, chemoresistant lymphomas can arise in the absence of substantial chromosomal insta-

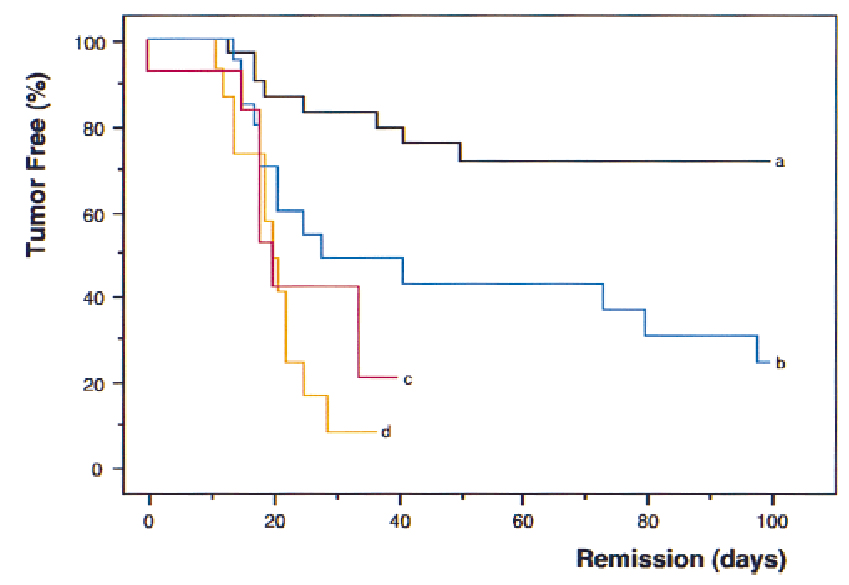

Figure 6. INK4a/ARF, p53, and long-term response to chemotherapy. Nontransgenic mice harboring reconstituted control $\left(n=60\right.$; black, a), INK4a $/ A R F^{-/-}(n=35$; blue, b), p53-/- $(n=14$;

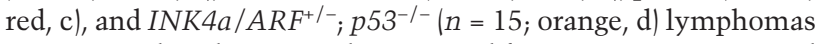
were treated with CTX and monitored for tumor regression and relapse. Importantly, CTX is not affected by classic multidrug resistance mechanisms that might complicate drug delivery. Tumor shrinkage to nonpalpability within 6 days after treatment is considered 'remission' and creates the tumor-free population at time 0 . Relapse was defined by recurrent palpable lymph node enlargement. Values were plotted in Kaplan-Meier survival curve format and presented as percentage of mice in remission over the time post-therapy. Note that the overall rate of treatment failure in control lymphomas $(-25 \%-30 \%)$ is consistent with the combined frequency of $I N K 4 a / A R F$ and $p 53$ mutations we observe in these tumors. 
bility. In turn, because INK4a/ARF mutations disable p53, the chromosomal instability observed in $p 53^{-/-}$ lymphomas appears dispensable for the aggressive behavior of these tumors.

More likely, the increased invasiveness and drug resistance of INK $4 a / A R F^{-/-}$and $p 53^{-/-}$lymphomas arises

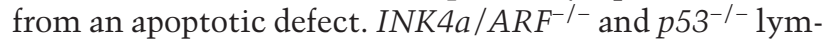
phomas displayed decreased apoptosis in situ and ex vivo (see Figs. 3 and 5), whereas there was no obvious relationship between tumor-cell genotype and proliferation, as measured by mitotic index in vivo, DNA content analysis ex vivo, and proliferation properties in vitro (see Fig. 3; data not shown). These results stand in contrast to an earlier report indicating that p53-null E $p 1-m y c$ lymphomas do not display an apoptotic defect (Hsu et al. 1995). Although we cannot explain this discrepancy, it is worth noting that disruption of apoptosis using a $b c l-2$ transgene is sufficient to accelerate Myc-induced tumorigenesis (Strasser et al. 1990). Moreover, ectopic expression of $b c l-2$ in the control lymphoma cells used in this study has no effect on proliferation but renders these cells highly invasive and chemoresistant following transplantation into syngenic mice (C.A. Schmitt and S.W. Lowe, unpubl.).

Although Epl-myc lymphomas harboring INK4a/ARF or p53 mutations are defective in CTX-induced cell death, CTX therapy induces complete remissions irrespective of p53 status. We suggest that the p53-independent death is due to apoptosis, because En-myc lymphomas expressing Bcl-2 are completely nonresponsive to CTX therapy at the maximally tolerated dose (C.A. Schmitt and S.W. Lowe, unpubl.). In contrast to CTX, doxorubicin fails to induce remissions in $p 53^{-/-}$lymphomas, although high doses induce p53-independent apoptosis in vitro (R.R. Wallace-Brodeur, M.E. McCurrach, and S.W. Lowe, unpubl.). Thus, the ability to achieve p53-independent killing depends on agent and dose. These data are consistent with the view that p53 is not an essential component of the apoptotic machinery but, rather, increases the probability that these agents trigger cell death (Lowe et al. 1993). In Ep-myc lymphomas, this increased propensity for apoptosis can determine tumor cure or relapse.

Our data have important implications for the understanding of the clinical behavior of human tumors. First, they provide compelling evidence that disruption of apoptosis during tumor development can simultaneously select for chemoresistant cells. This pattern of coselection may explain why some tumors are de novo 'resistant' despite having no prior exposure to drug and why it is difficult to separate the impact of p53 mutations on treatment sensitivity from its contribution to overall patient prognosis. Second, our results demonstrate that tumors with extragenic mutations in the p53 pathway can display properties of p53 mutant tumors. This fundamental point is crucial for interpreting studies relating p53 mutations to clinical parameters in human patients, which typically classify tumors strictly by p53 gene or protein status. Our data imply that a substantial number of p53 'normal' tumors would be misclassified by this approach (e.g., those harboring $A R F$ mutations) and may explain why some studies fail to correlate $p 53$ mutations with adverse clinical features (for review, see Brown and Wouters 1999).

This study provides the first evidence that INK4a/ $A R F$ mutations can have a negative impact on the outcome of cancer therapy and suggests that this defect arises from the failure of drugs to appropriately activate p53. Consequently, these data predict that disruption of the INK4a/ARF locus will contribute to chemoresistance in human tumors. As for p53 mutations, it seems likely that the overall impact of INK4a/ARF disruption on chemoresistance will depend on additional factors, such as tissue type, agent, and the mutational background of the tumor (for review, see Wallace-Brodeur and Lowe 1999; also see Bunz et al. 1999). However, it is noteworthy that p53 mutations are strongly associated with highly aggressive tumors and chemoresistance in human hematologic malignancies (e.g., see Elrouby et al. 1993; Diccianni et al. 1994; Fan et al. 1994; Wattel et al. 1994; Wilson et al. 1997), indicating that Ep1-myc lymphomas can recapitulate the behavior of human tumors. Therefore, we anticipate that this model will be useful for testing strategies to counter p53 and INK4a/ARF mutations in hematologic malignancies and other cancers.

\section{Materials and methods}

Mouse strains and tumor monitoring

All animal protocols used in this study were approved by the Cold Spring Harbor Laboratory Animal Care and Use Committee. Ell-myc transgenic mice (C57BL/6 inbred strain) and $\mathrm{Rb}^{-/-}$, INK4a/ARF $F^{-1-}$, and $p 53^{-/-}$mice $(\mathrm{C} 57 \mathrm{BL} / 6 \times 129 / \mathrm{sv})$ were crossed, and the offspring was genotyped by allele-specific PCR (Jacks et al. 1992, 1994; Serrano et al. 1996). Transgenic mice of the $F_{1}$ generation (pooled from the different crosses) or transgenics being heterozygous for the named loci were monitored twice a week by palpation of the prescapular and cervical lymph nodes. Enlargements of at least $5 \mathrm{~mm}$ in the longest diameter were considered 'well palpable' and reflect malignant disease. For determining white blood cell status, blood smears and $20 \mu \mathrm{l}$ of peripheral blood were obtained by tail artery bleeding. After ammoniumchloride hemolysis of the PBS-diluted and $\mathrm{K}_{3}-$ EDTA-anticoagulized blood sample, white blood cells were counted in a hemocytometer. Blood smears were fixed and stained using the Leukostat kit (Fisher Diagnostics). Mice having $\mathrm{WBC}>3 \times 10^{5} / \mu \mathrm{l}$ and being positive for lymphoblastic cells in the blood stream were considered 'leukemic'.

\section{Histopathology}

Animals harboring control, $\mathrm{Rb}^{+/-}, \mathrm{INK} 4 \mathrm{a} / \mathrm{ARF}^{-/-}$, and $\mathrm{p} 53^{-/-}$ lymphomas were sacrificed when prescapular lymph nodes reached a well-palpable size. Paraffin-embedded $(7 \mu \mathrm{m}), 4 \%$ neutral-buffered formalin-fixed tissue sections derived from lymph nodes and lung and liver specimens were stained with hematoxyilin-eosin (HE) to evaluate apoptotic nuclear morphology and invasiveness of lymphoma cells into visceral organs.

Lymphoma characterization, $\mathrm{LOH}$ analysis, and RT-PCR sequencing

After $\mathrm{CO}_{2}$ euthanasia, lymph nodes were dissected, minced in 
PBS, and filtered through a $35-\mu m$ nylon mesh. Single cell suspensions of freshly harvested lymphomas were immunophenotyped by flow cytometry using antibodies directed against Thy1.2, B220, and IgM (Pharmingen). Pre-B-cell lymphomas are Thy- $1.2^{-}, \mathrm{B}_{2} 20^{+}$, and $\mathrm{IgM}^{-}$, whereas mature B-cell lymphomas are Thy-1.2-, $\mathrm{B}_{220^{+}}$, and $\mathrm{IgM}^{+}$. To determine the mutational status of various genes, primary lymphoma cells were subjected to short-term culturing to eliminate normal cell contamination. Loss of the remaining wild-type allele [loss of heterozygosity $(\mathrm{LOH})]$ in tumors arising in mice being heterozygous for an indicated tumor suppressor locus was detected by allele-specific PCR (Jacks et al. 1992, 1994; Serrano et al. 1996). Exons 4-8 of the $p 53$ gene were sequenced by dye termination in an automated sequencer (Perkin-Elmer) after reverse transcription (SuperScript, GIBCO BRL) and PCR amplification of lymphoma cell total RNA. Finally, the gross integrity of the INK4a/ARF locus was assessed using PCR of exons $1 \beta$ and exon 2 in a multiplex PCR reaction harboring primers to a positive control.

\section{Lymphoma cell culture and in vitro treatment}

Single cell suspensions of freshly extracted lymphoma cells (see above) were plated on irradiated (30 Gy) feeder layer $\left(10^{6} \mathrm{NIH}\right.$ 3 T3 cells $/ 2.4-\mathrm{cm}$ plate) in $45 \%$ Iscove's modified Eagle medium, 45\% Dulbecco's minimal essential medium, 10\% fetal bovine serum, $100 \mathrm{U} / \mathrm{ml}$ penicillin and streptomycin, $4 \mathrm{~mm}$ L-glutamine, and $25 \mu \mathrm{M}$ 2-mercaptoethanol. For in vitro drug assays, mafosphamide (cyclohexylammonium salt, a CTX analog active in vitro; a generous gift from Asta Medica, Germany) was added at $0,0.3,3$, and $30 \mu \mathrm{g} / \mathrm{ml}$, and viability was measured (see below) $24 \mathrm{hr}$ later.

\section{Assessment of viability, cell-cycle parameters, and apoptosis}

Viability of short-term cultured lymphoma cells was analyzed by trypan blue dye exclusion. For analysis of ploidy, apoptosis (as percentage of cells in sub- $\mathrm{G}_{1}$ peak), and proliferation (as percentage of viable cells in S phase), $10^{6}$ ethanol-fixed lymphoma cells were incubated for $30 \mathrm{~min}$ at room temperature in $1 \mathrm{ml}$ of DNA staining solution $(200 \mu \mathrm{g}$ of propidium iodide and $2 \mathrm{mg}$ of RNase in $10 \mathrm{ml}$ of PBS), and DNA content was measured at 488 $\mathrm{nm}$ in a flow cytometer (FACScalibur, Becton Dickinson). In situ proliferation was estimated by counting of mitotic figures (cells in anaphase or telophase) relative to cell number in HEstained lymphoma sections (four samples each genotype, seven different fields, 200 cells each). In situ apoptosis was visualized in lymphoma sections by HE staining and a fluorescence-based TUNEL assay. TUNEL assays were performed in accordance to the manufacturer's protocol (Boehringer Mannheim). Leukemias were analyzed for apoptotic nuclear morphology by fluorescence microscopy after ethanol fixation and DAPI $\left(4^{\prime}, 6-\mathrm{Di}-\right.$ amidino-2-phenylindole) staining of peripheral blood samples.

\section{Western blotting analysis}

Whole-cell lymphoma cell or normal splenocyte lysates were generated by lysing of extracted cells in SDS sample buffer 160 $\mathrm{mm}$ Tris- $\mathrm{HCl}$ at $\mathrm{pH} 6.8,10 \%$ glycerol, $2 \%$ SDS, and 5\% 2-mercaptoethanol). Samples corresponding to $60 \mu \mathrm{g}$ of protein (BioRad Bradford protein assay) were separated on a SDS-polyacrylamide gel and transferred to Immobilon-P membranes (Millipore). p53 was detected using the polyclonal antibody CM5 (Novocastra, 1:2000 dilution), p21 using the polyclonal antibody C-19 (Santa Cruz, 1:500 dilution), and $\alpha$-tubulin using the monoclonal antibody B-5-1-2 (Sigma, 1:2000 dilution). Protein detection was visualized by ECL (Amersham) or Supersignal (Pierce).

\section{Lymphoma reconstitution and in vivo treatment}

Immediately after extraction, $10^{6}$ lymphoma cells in $100 \mu \mathrm{l}$ of PBS were reconstituted by tail vein injection into genetically matched, nontransgenic recipient mice /two mice per individual lymphoma sample) to monitor response to treatment. Tumors derived from the INK4a/ARF $F^{+-}$and $p 53^{+/-}$backgrounds were reconstituted in C57BL/6 $\times 129 /$ sv mice (Jackson Laboratories). CTX was applied as a single $300-\mathrm{mg} / \mathrm{kg}$ dose i.p. when arising tumors became well palpable.

\section{Statistical evaluation}

Tumor onset data reflect the time between birth and first-time palpability of enlarged lymph nodes; treatment response data reflect the time between remission and relapse as first-time palpability of a recurrent lymph node enlargement. Individual time values were plotted in the Kaplan-Meier population-eventtime course format and compared using the log-rank (MantelCox) test. Comparisons of means and standard deviations (s.D.) were performed using the unpaired $t$-test. Ploidy, cell cycle distribution, and sub-G1 content were analyzed using the ModFit LT 2.0 software.

\section{Acknowledgments}

We thank T. Jacks for the $R b^{+/-}$and $p 53^{-/-}$mice; M. Serrano and D. Beach for the $I N K 4 a / A R F^{-/-}$mice; A. Harris for the E $p-m y c$ transgenic mice; K. Sokol for histopathology; L. Bianco and the CSHL animal facility for technical assistance; M. Ockler and J. Duffy of the CSHL Graphic Arts facility for help with the artwork; G. Ferbeyre, A. Lin, M. Soengas, and A. Samuelson for editorial advice; and M. Roussel, C. Sherr, and J. Cleveland for discussion of unpublished data. This work was supported by a Dr. Mildred Scheel Cancer Foundation fellowship (C.A.S), a DOD Breast Cancer Research fellowship (E.d.S.), a Kimmel Scholar Award (S.W.L.), and a grant (CA13106) from the National Cancer Institute (S.W.L.).

The publication costs of this article were defrayed in part by payment of page charges. This article must therefore be hereby marked 'advertisement' in accordance with 18 USC section 1734 solely to indicate this fact.

\section{References}

Adams, J.M. and S. Cory. 1991. Transgenic models for haemopoietic malignancies. Biochim. Biophys. Acta 1072: 9-31.

Adams, J.M., A.W. Harris, C.A. Pinkert, L.M. Corcoran, W.S. Alexander, S. Cory, R.D. Palmiter, and R.L. Brinster. 1985. The c-myc oncogene driven by immunoglobulin enhancers induces lymphoid malignancy in transgenic mice. Nature 318: 533-538.

Bates, S., A.C. Phillips, P.A. Clark, F. Stott, G. Peters, R.L. Ludwig, and K.H. Vousden. 1998. p14ARF links the tumour suppressors RB and p53. Nature 395: 124-125.

Beroud, C. and T. Soussi. 1998. p53 gene mutation: Software and database. Nucleic Acids Res. 26: 200-204.

Brown, J.M. and B.G. Wouters. 1999. Apoptosis, p53, and tumor cell sensitivity to anticancer agents. Cancer Res. 59: 13911399.

Bunz, F., P.M. Hwang, C. Torrance, T. Waldman, Y. Zhang, L. Dillehay, J. Williams, C. Lengauer, K.W. Kinzler, and B. Vogelstein. 1999. Disruption of p53 in human cancer cells alters the responses to therapeutic agents. J. Clin. Invest. 104: 263-269. 
de Stanchina, E., M.E. McCurrach, F. Zindy, S.Y. Shieh, G. Ferbeyre, A.V. Samuelson, C. Prives, M.F. Roussel, C.J. Sherr, and S.W. Lowe. 1998. E1A signaling to p53 involves the p19 ${ }^{\mathrm{ARF}}$ tumor suppressor. Genes \& Dev. 12: 2434-2442.

Diccianni, M.B., J. Yu, M. Hsiao, S. Mukherjee, L.E. Shao, and A.L. Yu. 1994. Clinical significance of p53 mutations in relapsed T-cell acute lymphoblastic leukemia. Blood 84: 3105-3112.

Eischen, C.M., J.D. Weber, M.F. Roussel, C.J. Sherr, and J.L. Cleveland. 1999. Disruption of the ARF-Mdm2-p53 tumor suppressor pathway in Myc-induced lymphomagenesis. Genes \& Dev. (this issue).

Elrouby, S., A. Thomas, D. Costin, C.R. Rosenberg, M. Potmesil, R. Silber, and E.W. Newcomb. 1993. p53 gene mutation in B-cell chronic lymphocytic leukemia is associated with drug resistance and is independent of MDR1/MDR3 gene expression. Blood 82: 3452-3459.

Fan, S.J., W.S. Eldeiry, I. Bae, J. Freeman, D. Jondle, K. Bhatia, A.J. Fornace, I. Magrath, K.W. Kohn, and P.M. Oconnor. 1994. p53 gene mutations are associated with decreased sensitivity of human lymphoma cells to DNA damaging agents. Cancer Res. 54: 5824-5830.

Giaccia, A.J. and M.B. Kastan. 1998. The complexity of p53 modulation: Emerging patterns from divergent signals. Genes \& Dev. 12: 2973-2983.

Haber, D.A. 1997. Splicing into senescence: The curious case of p16 and p19 ARF. Cell 91: 555-558.

Hermeking, H. and D. Eick. 1994. Mediation of c-myc induced apoptosis by p53. Science 265: 2091-2093.

Hsu, B., M.C. Marin, A.K. Elnaggar, L.C. Stephens, S. Brisbay, and T.J. Mcdonnell. 1995. Evidence that c-myc mediated apoptosis does not require wild-type p53 during lymphomagenesis. Oncogene 11: 175-179.

Jacks, T., A. Fazeli, E.M. Schmitt, R.T. Bronson, M.A. Goodell, and R.A. Weinberg. 1992. Effects of an Rb mutation in the mouse. Nature 359: 295-300.

Jacks, T., L. Remington, B.O. Williams, E.M. Schmitt, S. Halachmi, R.T. Bronson, and R.A. Weinberg. 1994. Tumor spectrum analysis in p53-mutant mice. Curr. Biol. 4: 1-7.

Jacobs, J.J.L., B. Scheijen, J.-W. Voncken, K. Kieboom, A. Berns, and M. van Lohuizen. (1999). Bmi-1 collaborates with c-Myc in tumorigenesis by inhibiting c-Myc induced apoptosis via Ink4a/ARF. Genes \& Dev. (This issue).

Jawhs, J.J.L., B. Scheijen, J.-W. Voncken, K. Kreboom, A. Berns, M. van Lohuizen. 1999. Bmi-1 collaborates with cMyc in tumorigenesis by inhibiting c-Myc induced apoptosis via INK4a/ARF. Genes \& Dev. (This issue).

Kamijo, T., F. Zindy, M.F. Roussel, D.E. Quelle, J.R. Downing, R.A. Ashmun, G. Grosveld, and C.J. Sherr. 1997. Tumor suppression at the mouse INK4a locus mediated by the alternative reading frame product p19 ${ }^{\mathrm{ARF}}$. Cell 91: 649-659.

Kamijo, T., J.D. Weber, G. Zambetti, F. Zindy, M.F. Roussel, and C.J. Sherr. 1998. Functional and physical interactions of the ARF tumor suppressor with p53 and Mdm2. Proc. Nat1. Acad. Sci. 95: 8292-8297.

Kastan, M.B., O. Onyekwere, D. Sidransky, B. Vogelstein, and R.W. Craig. 1991. Participation of p53 protein in the cellular response to DNA damage. Cancer Res. 51: 6304-6311.

Kastan, M.B., Q. Zhan, W.S. el-Deiry, F. Carrier, T. Jacks, W.V. Walsh, B.S. Plunkett, B. Vogelstein, and A. Fornace Jr. 1992. A mammalian cell cycle checkpoint pathway utilizing p53 and GADD45 is defective in ataxia-telangiectasia. Cell 71: $587-597$

Lowe, S.W. and H.E. Ruley. 1993. Stabilization of the p53 tumor suppressor is induced by adenovirus E1A and accompanies apoptosis. Genes \& Dev. 7: 535-545.
Lowe, S.W., H.E. Ruley, T. Jacks, and D.E. Housman. 1993 p53-dependent apoptosis modulates the cytotoxicity of anticancer agents. Cell 74: 954-967.

Palmero, I., C. Pantoja, and M. Serrano. 1998. p19 ${ }^{\text {ARF }}$ links the tumour suppressor p53 to Ras. Nature 395: 125-126.

Pomerantz, J., N. Schreiber-Agus, N.J. Liegeois, A. Silverman, L. Alland, L. Chin, J. Potes, K. Chen, I. Orlow, H.W. Lee, C. Cordon-Cardo, and R.A. DePinho. 1998. The INK4a tumor suppressor gene product, p19 ${ }^{\mathrm{ARF}}$, interacts with MDM2 and neutralizes MDM2's inhibition of p53. Cell 92: 713-723.

Prives, C. 1998. Signaling to p53: Breaking the MDM2-p53 circuit. Cell 95: 5-8.

Ruas, M. and G. Peters. 1998. The p16INK4a/CDKN2A tumor suppressor and its relatives. Biochim. Biophys. Acta 1378: F115-F177.

Schmitt, C.A. and S.W. Lowe. 1999. Apoptosis and therapy. I. Pathol. 187: 127-137.

Serrano, M., G.J. Hannon, and D. Beach. 1993. A new regulatory motif in cell-cycle control causing specific inhibition of cyclin D/CDK4. Nature 366: 704-707.

Serrano, M., H. Lee, L. Chin, C. Cordon-Cardo, D. Beach, and R.A. DePinho. 1996. Role of the INK4a locus in tumor suppression and cell mortality. Cell 85: 27-37.

Serrano, M., A.W. Lin, M.E. McCurrach, D. Beach, and S.W. Lowe. 1997. Oncogenic ras provokes premature cell senescence associated with accumulation of $\mathrm{p} 53$ and $\mathrm{p} 16^{\text {INK4a }}$ Cell 88: 593-602.

Sherr, C.J. 1998. Tumor surveillance via the ARF-p53 pathway. Genes \& Dev. 12: 2984-2991.

Stott, F.J., S. Bates, M.C. James, B.B. McConnell, M. Starborg, S. Brookes, I. Palmero, K. Ryan, E. Hara, K.H. Vousden, and G. Peters. 1998. The alternative product from the human CDKN2A locus, p14 ${ }^{\mathrm{ARF}}$, participates in a regulatory feedback loop with p53 and MDM2. EMBO J. 17: 5001-5014.

Strasser, A., A.W. Harris, M.L. Bath, and S. Cory. 1990. Novel primitive lymphoid tumours induced in transgenic mice by cooperation between myc and bcl-2. Nature 348: 331-333.

Tao, W. and A.J. Levine. 1999. P19 ${ }^{\mathrm{ARF}}$ stabilizes p53 by blocking nucleo-cytoplasmic shuttling of Mdm2. Proc. Natl. Acad. Sci. 96: 6937-6941.

Wallace-Brodeur, R.R. and S.W. Lowe. 1999. Clinical implications of p53 mutations. Cell Mol. Life Sci. 55: 64-75.

Wattel, E., C. Preudhomme, B. Hecquet, M. Vanrumbeke, B. Quesnel, I. Dervite, P. Morel, and P. Fenaux. 1994. p53 mutations are associated with resistance to chemotherapy and short survival in hematologic malignancies. Blood 84: 31483157.

Weber, J.D., L.J. Taylor, M.F. Roussel, C.J. Sherr, and D. BarSagi. 1999. Nucleolar Arf sequesters Mdm2 and activates p53. Nature Cell Biol. 1: 20-26.

Wilson, W.H., J. Teruya-Feldstein, T. Fest, C. Harris, S.M. Steinberg, E.S. Jaffe, and M. Raffeld. 1997. Relationship of p53, bcl-2, and tumor proliferation to clinical drug resistance in non-Hodgkin's lymphomas. Blood 89: 601-609.

Zhang, Y. and Y. Xiong. 1999. Mutations in human ARF exon 2 disrupt its nucleolar localization and impair its ability to block nuclear export of MDM2 and p53. Mol. Cell 3: 579591.

Zhang, Y., Y. Xiong, and W.G. Yarbrough. 1998. ARF promotes MDM2 degradation and stabilizes p53: ARF-INK4a locus deletion impairs both the $\mathrm{Rb}$ and $\mathrm{p} 53$ tumor suppression pathways. Cell 92: 725-734.

Zindy, F., C.M. Eischen, D.H. Randle, T. Kamijo, J.L. Cleveland, C.J. Sherr, and M.F. Roussel. 1998. Myc signaling via the ARF tumor suppressor regulates p53-dependent apoptosis and immortalization. Genes \& Dev. 12: 2424-2433. 


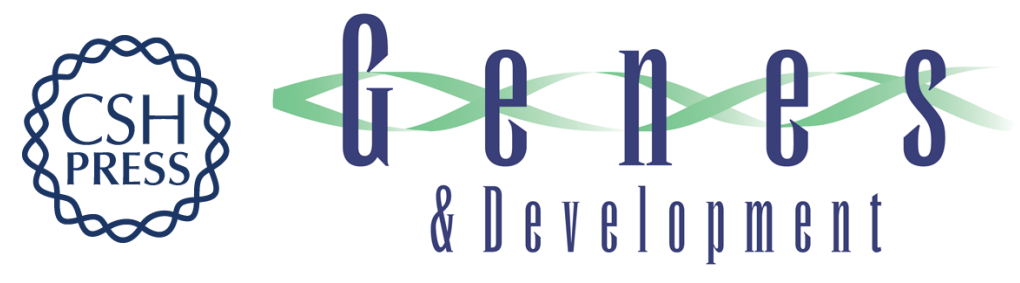

\section{INK4a/ARF mutations accelerate lymphomagenesis and promote chemoresistance by disabling p53}

Clemens A. Schmitt, Mila E. McCurrach, Elisa de Stanchina, et al.

Genes Dev. 1999, 13:

References This article cites 41 articles, 16 of which can be accessed free at:

http://genesdev.cshlp.org/content/13/20/2670.full.html\#ref-list-1

License

Email Alerting

Receive free email alerts when new articles cite this article - sign up in the box at the top

Service right corner of the article or click here.

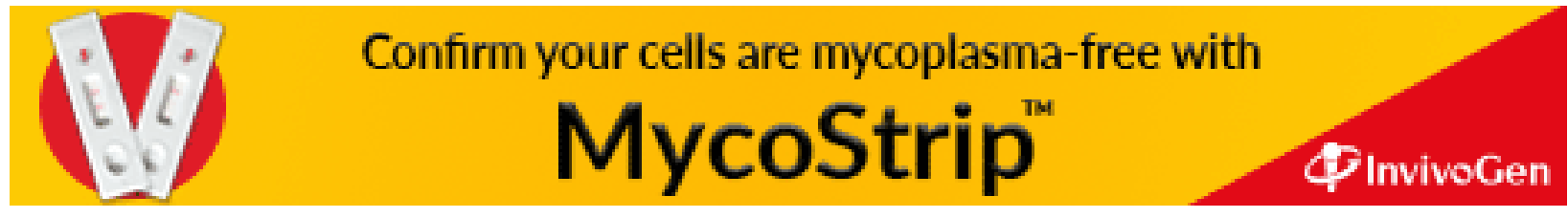

